\title{
Laboreal
}

Volume $12 \mathrm{~N}^{\circ} 1$ | 2016

Os Equipamentos de Proteção Individual (EPI):

protetores, mas nem sempre

\section{(Acerca De La) Pereza}

(Sobre A) Preguiça

(À Propos De La) Paresse

(About) Laziness

\section{Suzana Albornoz}

\section{(2) OpenEdition}

\section{Journals}

Edición electrónica

URL: http://journals.openedition.org/laboreal/3428

DOI: $10.4000 /$ laboreal.3428

ISSN: 1646-5237

Editor

Universidade do Porto

Referencia electrónica

Suzana Albornoz, "(Acerca De La) Pereza », Laboreal [En línea], Volume 12 NN$^{0} 1$ | 2016, Publicado el 01 julio 2016, consultado el 14 septiembre 2020. URL : http://journals.openedition.org/laboreal/3428

Este documento fue generado automáticamente el 14 septiembre 2020.

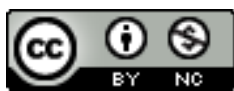

Laboreal está licenciado com uma Licença Creative Commons - Atribuição-NãoComercial 4.0 Internacional. 


\title{
(Acerca De La) Pereza
}

\author{
(Sobre A) Preguiça \\ (À Propos De La) Paresse \\ (About) Laziness
}

Suzana Albornoz

\section{NOTA DEL EDITOR}

http://dx.doi.org/10.15667/laborealxii0116saes

1 Hablar seriamente de este concepto - pereza - requiere abandonar prejuicios y límites estrictos, abrir la mente y cruzar el plano de saberes y discursos, a partir de las antesalas de la doctrina religiosa tradicional y la filosofía moral clásica hasta la realidad concreta, en la observación de la vida social presente.

El hecho es que, en la herencia bíblica y cristiana (una presencia todavía muy fuerte en esta época cosmopolita y multicultural, incluso en nuestro sincrético y mestizado Brasil que lo es también en el plano espiritual) la pereza ocupa un lugar destacado entre los vicios. Para el sentido común o la ideología dominante, en términos de valores y normas, la pereza se incluye entre los siete pecados capitales y no sólo se ve como un defecto grave, sino que también se considera "la madre de todos los vicios".

3 Por una parte, en el mundo católico (que echó raíces en el sur de Europa, en el borde del mar Mediterráneo, de donde vinieron conquistadores e inmigrantes), quizás por supervivencias paganas, parece haber disfrutado del dolce far niente y de la siesta, y, en tiempos de monasterios, el silencio y la calma de la casa de retiro seguramente fueron favorables para la oración y la contemplación, esenciales para la mejora del mundo interno. Por otra parte, en la época moderna, los reformadores del cristianismo de los países más al norte, y de los cuales también recibimos inmigración e influencias ideológicas, comenzaron a dar un nuevo peso moral a la actividad, a la profesión y al trabajo, como una expresión de lealtad, como una virtud e incluso como una condición para la salvación. 
4 Debe recordarse que en la antigua Grecia de los primeros filósofos se valoraba más el ocio que el trabajo (función de los esclavos) y se creía que del ocio surgiría el pensamiento, la capacidad de pensar y de opinar. Aquello que los griegos concebían como skholé probablemente no era idéntico a lo que hoy entendemos como ocio, entretenimiento y tiempo libre y seguramente no tenía el peso moral de la pereza prohibida. En realidad, parece haber sido apreciado como una condición importante para el aprendizaje y la creación - el concepto skholé está en el origen de la palabra escuela. Esta carga positiva del ocio según los antiguos griegos llegó hasta nosotros a través de la cultura latina e ibérica y se puede considerar como un antídoto contra la obsesión con el trabajo de los tiempos modernos - obsesión por cierto rentable y útil, especialmente para los propietarios de los medios de producción y los explotadores de mano de obra.

5 Nuestro gran continente latinoamericano (incluyendo el modo de vida brasileño y tropical) no se restringió a las influencias culturales del Viejo Mundo a las que nos hemos referido antes. Desde luego en nuestra mezcla de herencias, bien expresada en el Macunaíma de Mario de Andrade (1986), asimilamos otras sustancias además de las que recibimos a través de la leche de nuestras madres indígenas y africanas, de manera que los rasgos y costumbres de la cultura más típica de nuestras regiones suavizaron la culpa asociada a la pereza por la doctrina protestante y nos permitieron disfrutar de más ocio en sus variaciones, conforme a la latitud y a la configuración de clase.

6 En cualquier caso, cuando salimos del plano de las normas, de la historia de las referencias tradicionales, religiosas o filosóficas y entramos en el plano concreto de la vivencia de los individuos en sus grupos y comunidades, pueblos o naciones, podemos percibir la evidente inseguridad y gran perplejidad, dada la dificultad en mantener el entendimiento habitual en este inicio de milenio, lleno de transformaciones, metamorfoseado por la globalización y la migración intensa y por la comunicación infinitamente potenciada por las nuevas tecnologías de la cibernética y de las redes digitales. Estos movimientos y cambios tecnológicos afectan sobre todo a la cuestión del trabajo y del descanso, por lo que también afectan a la importancia de los valores de la disciplina, de la aplicación y de la pereza.

7 Nuestro tiempo ha sido llamado, tal vez un poco apresuradamente, de era post-industrial, en el sentido de que hoy en día ya no es la mayoría de la población que gira en torno la producción industrial. La gran mayoría se ocupa en los servicios y muchos quedan fuera del mundo de la producción. Sin embargo, en todas partes seguimos viviendo una fuerte presión por el trabajo, por la afirmación humana a través del trabajo y de la producción material o "inmaterial", aunque el nivel de automatización ha llegado a un punto que, en rigor, toda la humanidad habitante del planeta Tierra podría trabajar menos y hasta producir menos.

8 La forma capitalista de organización económica (a causa de los intereses propios y de la propaganda con ánimo de lucro) no favorece el reconocimiento de que la humanidad ya podría trabajar y producir menos. Seguimos juzgándonos por la cantidad que producimos y caemos en la trampa de considerar negativamente, como pecado de la pereza, el descanso necesario para el mantenimiento de la salud y tal vez incluso la liberación de la actividad profesional tras décadas de trabajo agotador. El testimonio de personas con necesidades especiales o con discapacidad así como de personas mayores o jubiladas, además de los niños, nos invita a revisar esta manera de juzgar el valor de la gente a través de la productividad. Esta revisión de criterios será importante para 
mirar de forma más comprensiva a las verdaderas multitudes de jóvenes desempleados que la automatización creó en el mundo, incluso en los países ricos y desarrollados.

El deseo de pleno empleo y la aceptación del trabajo y del descanso bien distribuidos (incluyendo por una parte, la afirmación de las personalidades por su capacidad creativa, y, por otra parte, el respeto del descanso o el "derecho a la pereza" para la salud y la elevación de la calidad de vida) obligan a que se reconsidere hoy la cuestión de la jornada de trabajo. Desde hace muchas décadas que, en términos nacionales e internacionales, las leyes laborales no evolucionan tanto como sería posible y no avanzan de manera efectiva en la conquista de más tiempo libre para los trabajadores. En las situaciones actuales de gran cambio, en rigor incontrolable y casi impredecible, las reglas estrictas parecen condenadas al fracaso. Sin embargo, es necesaria una toma de conciencia y reflexión al respecto.

La reducción de la jornada de trabajo es una bandera que se basa en nuevas condiciones objetivas y concretas y que se puede hacer valer. La conquista de un nuevo derecho a la pereza como más tiempo libre para el descanso, para el cuidado de uno mismo y la restauración y también como el ocio creativo del que habla Domenico De Masi (2000) (para el estudio, la cultura, el entretenimiento, la creación artística, el deporte, el viaje, la participación política) es un objetivo posible para los trabajadores de hoy en día. Este tiempo libre para la pereza fuera del trabajo (entendido no como un vicio, sino como una condición para una vida más sana y significativa) es parte de la utopía humanista de un mundo mejor para los hombres que trabajan y viven de su esfuerzo y no de la explotación de la fuerza de trabajo ajena. Permanece como una forma específica de utopía concreta que debe ser vista con esperanza y determinación.

Dado que la pereza, a lo largo de los milenios cristianos, se ha considerado un pecado o un vicio desde el punto de vista moral, pero también se pudo considerar, en otras épocas, como ocio y oportunidad para el placer, el pensamiento y la creación, se puede entender que la valoración del "no hacer nada" queda abierta y depende de lo que usamos como tabla de valores y como instrumento de medición.

Por otro lado, la estricta supervivencia de la especie humana, con las máquinas inteligentes de que disponemos y en perfeccionamiento constante, requiere hoy en día menos trabajo colectivo y menos producción, menos industria y agresión a la naturaleza. Es decir, la base material no determina un aumento del esfuerzo productivo y es lógico pensar en la apertura de más tiempo libre para cada uno de los habitantes del planeta. Tiempo libre para la recuperación del esfuerzo: para convivir con la naturaleza, para disfrutar de la salud y el desarrollo a través del deporte; para disfrutar de las nuevas posibilidades de comunicación, transporte y turismo; para las nuevas formas de experimentar el arte, las obras y eventos culturales; para la invención de nuevas formas de convivencia comunitaria y participación en la vida de la ciudad; para todo lo que dignifica y eleva la experiencia humana más allá de la mera supervivencia y del trabajo productivo.

Ante esta revelación que se podría recibir como una novedad histórica positiva (la de que no se necesitan tantos brazos humanos para proveer los alimentos y medios de vida a la multitud) ¿por qué la reacción es la de preocupación y no de celebración? ¿Por qué no se recibe con alegría la noticia de que hay ciudadanos sin trabajo que podrían dedicarse a las cosas buenas propias del entretenimiento, de la cultura y del tiempo libre? ¿Por qué se preocupan tanto las administraciones públicas por los muchos jóvenes que no han sido integrados en el llamado mercado de trabajo? La educación 
pretende dar respuesta a este reto, tratando de mantener a los jóvenes más tiempo en las instituciones educativas. Sin embargo, el impulso hacia la autonomía e independencia en relación con las familias de origen exige una fuente de ingresos propia, generalmente asociada a una actividad profesional.

La comprensión de los datos, la interpretación de las estadísticas de empleo y desempleo en nuestro tiempo no es algo sencillo. La prensa suele hacer un uso simplificado de los datos estadísticos, que a menudo se convierten en un instrumento ideológico, pero los datos del desempleo son difíciles de interpretar. Por ejemplo, hace algunas décadas, una parte importante de la población - las mujeres - era a menudo omitida u olvidada en las estadísticas de empleo y desempleo, a pesar de que muchas mujeres ya estaban integradas en la industria, en la agricultura e incluso en las profesiones liberales y en los servicios. Por este motivo, es difícil comparar los datos de desempleo femenino en diferentes épocas, ya que hasta hace poco la profesionalización femenina se trataba de forma distinta, especialmente en la edad más productiva que coincide con la edad reproductiva.

El nuevo análisis y la búsqueda de soluciones para el problema del empleo y del desempleo en el mundo contemporáneo, en este comienzo de la era post-industrial, considerarán una relación más equilibrada entre el esfuerzo y el descanso, entre la aplicación productiva y el ocio. Primero, no se puede considerar al desempleo como pereza de la población o interpretarlo como falta de voluntad para trabajar. Por un lado, puede existir una inadecuación, un desfase entre la preparación y la exigencia de las nuevas realidades, observándose una falta de preparación para las nuevas actividades requeridas, incluso para las nuevas profesiones que surgen como resultado de las nuevas situaciones relacionadas con las nuevas tecnologías. Pero el problema principal radica en la distribución de los ingresos, en la manera de organizar el acceso a ellos cuando hay menos empleo y menos necesidad de trabajo y, por lo tanto, en la forma de garantizar a todos, incluyendo aquellos que no tienen acceso al empleo, los medios de acceso a los bienes y servicios necesarios para su supervivencia y una vida digna y plena.

16 Es en este punto donde se encuentran la realidad y el sueño humano de una vida más plena de realización y felicidad. Y es ahí donde se unen la noción de la pereza y la de ocio o entretenimiento, como el otro lado del trabajo humanizado, que se constituye una franja utópica, para recordar las expresiones de la filosofía de la utopía concreta de Ernst Bloch $(2005,2006)$. En estos márgenes poco definidos de la realidad se concentran posibilidades, la abertura hacia lo nuevo y promesas de un futuro deseable y aún por realizar. El país imaginario donde la miel gotea de los árboles (la Schlaraffenland o el País de Cucaña medieval, la Tierra sin Males del pueblo Guaraní) puede existir, al menos en parte. Y siempre servirá como fuente de inspiración y fuerza para las nuevas generaciones en la lucha por una mejor distribución del esfuerzo y del descanso, por la reducción de la jornada de trabajo y por el derecho a la pereza creativa. 


\section{BIBLIOGRAFÍA}

Albornoz, S. (2006, $2^{\mathrm{a}}$ ed.). Ética e utopia. Ensaio sobre Ernst Bloch. Porto Alegre/ Santa Cruz do Sul: Movimento/ Edunisc.

Albornoz, S. (2011). Trabalho e utopia na modernidade: de Thomas More a Paul Lafargue. Porto Alegre/ Nova Petrópolis: Movimento/Nova Harmonia.

Andrade, M. de (1986, 22ª̣ed.). Macunaíma: o herói sem nenhum caráter. Belo Horizonte: Itatiaia.

Bloch, E. (2005, 2006). O Princípio Esperança (I, II, III). Rio de Janeiro: Contraponto.

De Masi, D. (2000). 0 ócio criativo. Rio de Janeiro: Sextante.

Lafargue, P. (1881/2005). Le Droit à la paresse. Paris: Allia.

Poty, V., \& Christidis, D. (2015). Os Guarani Mbyá. Porto Alegre: Wences Design Criativo.

\section{ÍNDICE}

Temas: o Dicionário

\section{AUTOR}

\section{SUZANA ALBORNOZ}

Departamento de Educação e Ciências do Comportamento, Universidade Federal do Rio Grande (FURG), Campus Carreiros, CEP 96201-900 Rio Grande - RS, Brasil 